\section{Implementation of a professional enrichment program to enhance medical school experience}

\author{
Linda R. Adkison, Andrea L. Hanson \\ Office of Curricular Affairs, Kansas City \\ University of Medicine and Biosciences, \\ Kansas City, MO, USA
}

\begin{abstract}
Medical students experience stress during medical education that can negatively impact performance. Typical curricula in U.S. medical schools are rigorously intense and provide little or no time off between courses in the first two years of training. This intensity contributes to increased stress for students accustomed to performing academically near the top of the class prior to matriculating in medical school. We describe an innovative new academic calendar that was modified to create a Professional Enrichment Program. Students can step back from the rigors of coursework and engage in several types of activities in order to decompress from recent studying and examinations. These activities include electives, service opportunities, independent study, and clinical experiences that are selfselected by students. Students and faculty complete surveys about the activities they completed and the usefulness of their choices. Results show broad approval of the program with the greatest results supporting an appreciation of time to decompress and an increase in time for family and personal activities.
\end{abstract}

\section{Background}

Studies have reported extensively on the high prevalence of depression, anxiety, and distress among medical students globally. ${ }^{1-4}$ In several U.S. studies on the consequences of psychological stressors, as many as $50 \%$ of students reported experiencing burnout and 10\% reported experiencing suicidal ideation..$^{5-7}$ It is readily recognized that excessive anxiety, depression, or distress adversely affects student academic performance. ${ }^{8}$ Stewart et al. ${ }^{9}$ showed that academic performance in medical school predicts stress independent of pre-medical school performance; students who performed well prior to medical school, which includes all medical students, can falter in medical school when stressors increase beyond an ability to manage the stressors. ${ }^{10,11}$ The inability to manage stress continues to impede academic performance if not resolved. ${ }^{12}$ Several studies report an improvement in student performance with stress reduction and intervention programs. ${ }^{13-17}$ Our data (unpublished) suggested any changes that decompressed the curriculum and enhanced the quality of family and personal life could improve the educational experience.

Our goal was to restructure the academic calendar within the existing curricular framework to facilitate better learning by reducing the intensity of the schedule. This redesign led to opportunities for students to self-direct their activities including pursuing clinical and research topics of interest. The premise was that creating a program to provide periodic separation between intense medical courses would allow students time to better appreciate the learning environment and decrease the consequences of the intense educational experience. The redesigned calendar provides a unique approach to medical education curricula which typically have few scheduled breaks during the academic year.

\section{Innovation}

Kansas City University of Medicine and Biosciences (KCUMB) delivers a multidisciplinary, integrated curriculum that underwent a calendar change in July 2009. The new calendar created time that could be used in several ways to improve the quality of personal and family life as well as the educational experience. Guidelines for the new program encouraged flexibility for individual student needs. There are six Professional Enrichment Program periods (PEP I-V and PEP-clinical). First year students have two PEPs of one-week duration. Second year students have four PEPs of two weeks duration (Table 1).

Prior to implementation of the Professional Enrichment Program (PEP), students completed two required elective credits before beginning the third year of training. These were usually completed during a four week period at the end of the second year that also included several required activities for clerkship preparation. An important consideration for the redesigned calendar was the federal regulation that curriculum is provided as a qualifier for student financial aid. ${ }^{18,19}$ In other words, students receive no financial aid for vacations. Therefore, a component of the new calendar was to provide electives and other curricular events during PEP weeks to maintain curriculum continuity. Accomplishing this fulfilled the requirements of external institutions lending tuition and living expenses to students.

To strengthen educational requirements supporting the PEP scheduling, the preclinical elective requirement was changed to four
Correspondence: Linda R. Adkison, Office of Curricular Affairs, Kansas City University of Medicine and Biosciences, 1750 Independence Avenue, Kansas City, M0 64106 USA.

Tel. +1.816.6547312 - Fax: +1.816.6547311

E-mail: ladkison@kcumb.edu

Key words: curriculum development, stress reduction, undergraduate electives, studentdirected learning.

Acknowledgements: the authors acknowledge the contributions of many who contributed to background studies supporting discussions and decisions to develop the Professional Enrichment Program. At Mercer University School of Medicine, Macon GA, these included Drs. Marie Dent, Allison Scheetz, Roberta Weintraut, Alice House, Jan LaBeause, and the late Dr. Donna Harris.

Conflict of interests: the authors report no potential conflict of interests.

Received for publication: 11 September 2012.

Revision received: 1 February 2013.

Accepted for publication: 1 March 2013.

This work is licensed under a Creative Commons Attribution NonCommercial 3.0 License (CC BYNC 3.0).

(C) Copyright L.R. Adkison and A.L. Hanson et al., 2013

Licensee PAGEPress srl, Italy

Medical Education Development 2013; 3:e3

doi:10.4081/med.2012.e3

semester credits. New one and two week electives were developed that aligned with educational competencies and objectives and that would not interfere with other course work. Students decide when to complete the elective requirement based upon electives offered and other events during PEPs, including personal or family needs. Elective credits are typically between 0.5 and 2.0 semester credits, or 8 to 25 contact hours, respectively. Credits earned have ranged from 4 to 13 semester credits, reflecting the individuality of the program.

Service is an expectation of all student organizations, and organizations often use PEP weeks for service projects or to attend national meetings that coincide with a scheduled PEP. Students receive no academic credit for service but these are value-added experiences and are aligned with the university mission to engage in research and service to improve the well-being of diverse communities. ${ }^{20,21}$ PEP weeks make it easier for more students to participate in these events than previously when events were scheduled after classes and attending national meetings required missing classes. 
Other opportunities are available for students to gain clinical experience. Students can schedule physician shadowing, observe autopsies, attend special lectures, or schedule time in the simulation laboratory. These experiences may lead students to select an elective with more extensive clinical interaction for which credit is earned. There were challenges to developing and delivering electives for large classes. Many faculty preferred offering electives for small groups for better student interaction rather than to a large class. To overcome the challenges of small group electives, faculty offer electives at multiple times during the year and are developing interactive, online electives to meet student interests.

\section{Evaluation}

The Professional Enrichment Program has completed three years. At the end of each PEP, all students are required to complete a survey about their experiences including how they used the time, the level of satisfaction with different opportunities, and the effect of the PEP experience on the quality of life as a student.

The number of electives offered and student participation in electives have increased since the beginning of the program (Figure 1). As students became more familiar with the program, they began shifting some organizational activities to PEPs to conflict less with required class schedules and studying. This increased student participation. Likewise, students were able to take advantage of clinical service experiences that were optional but more difficult to take advantage of during periods of required classes. Figure 2 shows that as the program has progressed, the percent of students reporting electives, independent study time, service learning opportunities, and community service opportunities were useful or very useful increased. Narrative feedback and focus groups were instrumental in directing improvements. Important in the design and implementation of the program was a desire to have a positive impact in student life. Figure 3 A shows a majority of students were satisfied

Table 1. Curriculum continuum for Year I and Year II. The Professional Enrichment Program (PEP) weeks are scheduled approximately every 12 weeks.

\begin{tabular}{ll}
\hline Year one & Year two \\
Orient & Neuroscience I \\
Foundation of medicine & Neuroscience II \\
\hline Musculoskeletal & PEP III \\
PEP I & Skin, blood and lymph \\
Cardiopulmonary I & Endocrine \\
\hline Cardiopulmonary I & PEP IV \\
PEP II & Reproduction and development \\
\hline Gastrointestinal & PEPV \\
Renal & PEP clinical \\
\hline
\end{tabular}

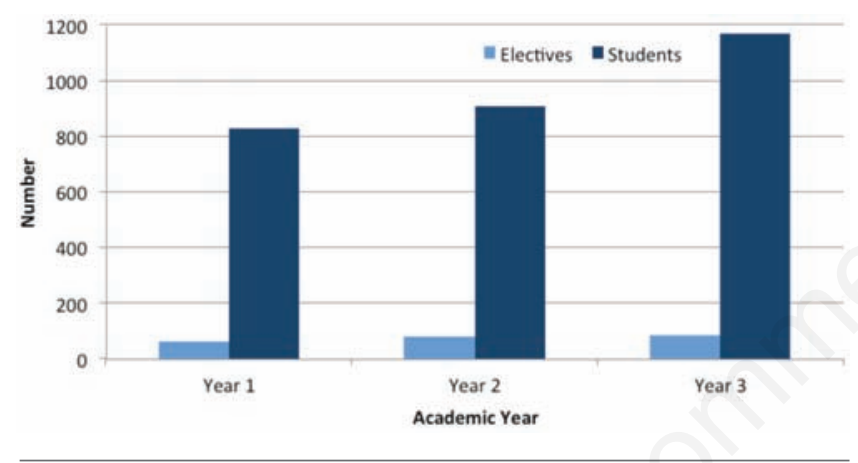

Figure 1. Elective participation. The number of electives have increased from 64 to 85 during the first three years of the Professional Enrichment Program. Participation has increased from 826 to 1167 enrolled students.

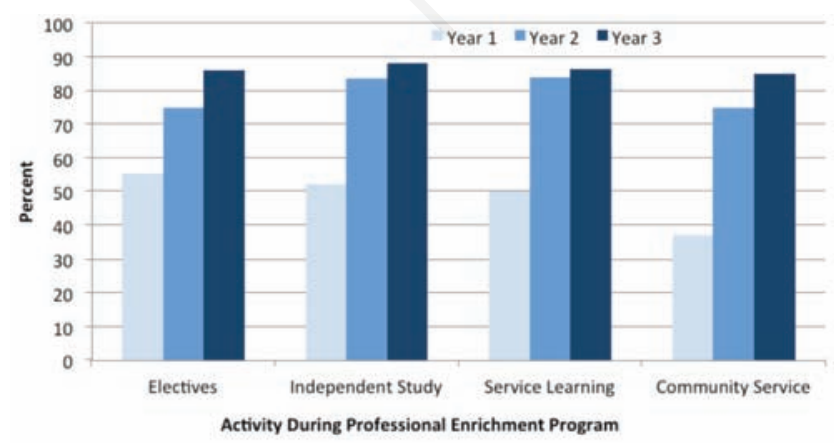

Figure 2. Percent of students in the Academic Year reporting activities were useful or very useful. Independent study are activities arranged by the student and not part of an organization or elective. Service learning includes those activities related to professional enrichment such as attending national meetings and clinical shadowing. Community service includes outreach projects arranged by university sponsored organizations.
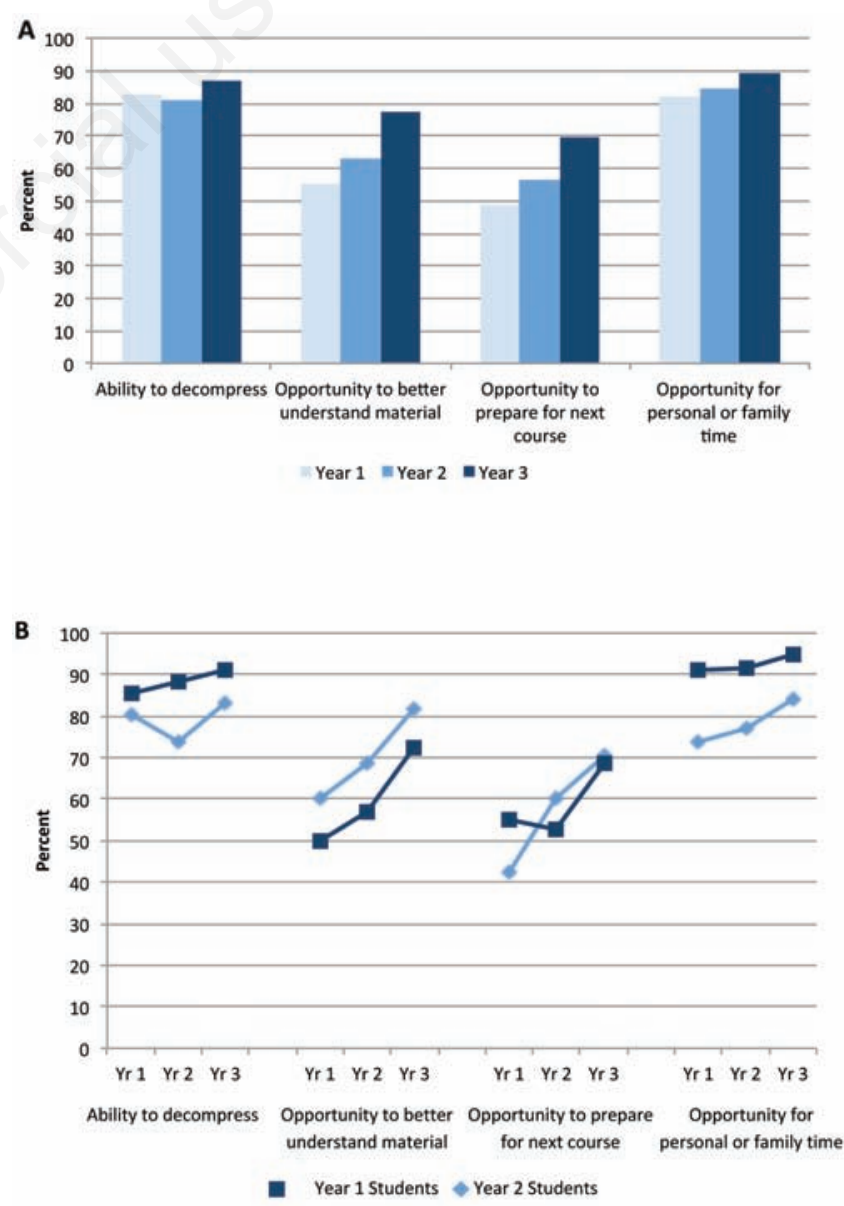

Figure 3. Student perception of Professional Enrichment Program impact. A) Percent of all students reporting they were satisfied or very satisfied. B) Data shown in A are segregated by first year and second year students reporting satisfied or very satisfied. 


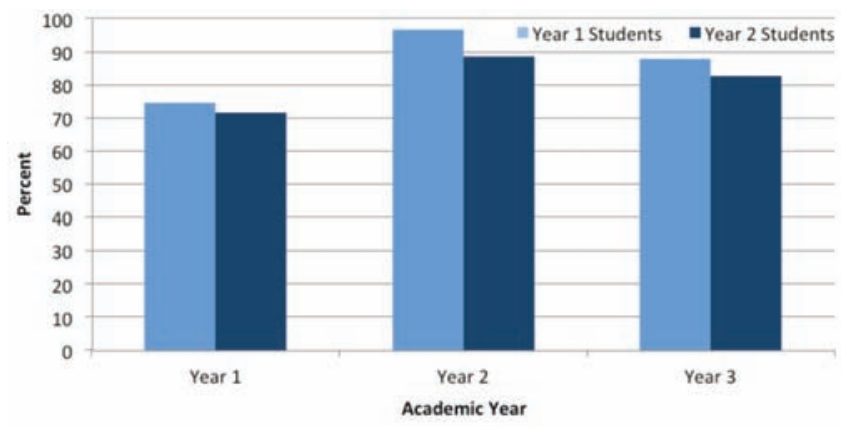

Figure 4. Percent of all students reporting satisfied or very satisfied with Professional Enrichment Program.

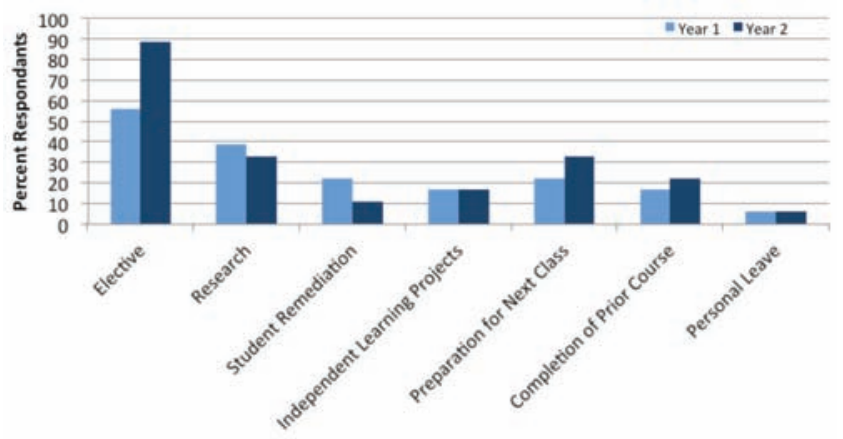

Figure 5. Faculty reported activities during Professional Enrichment Program weeks.

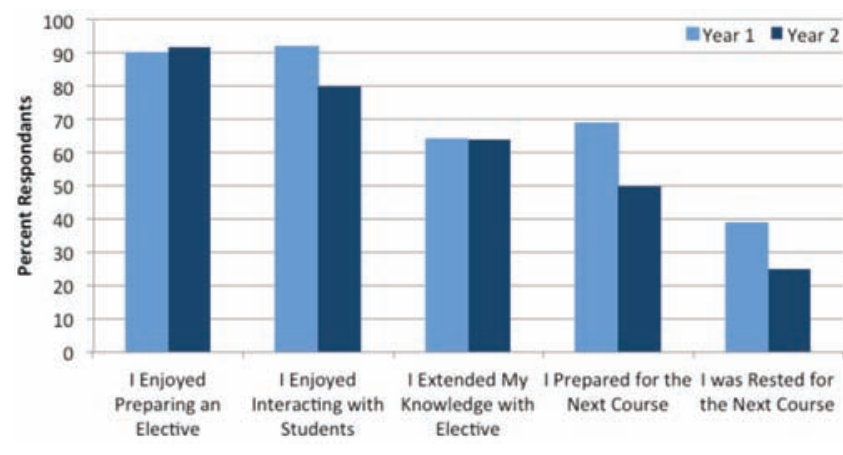

Figure 6. Faculty reporting agree or strongly agree with statements.

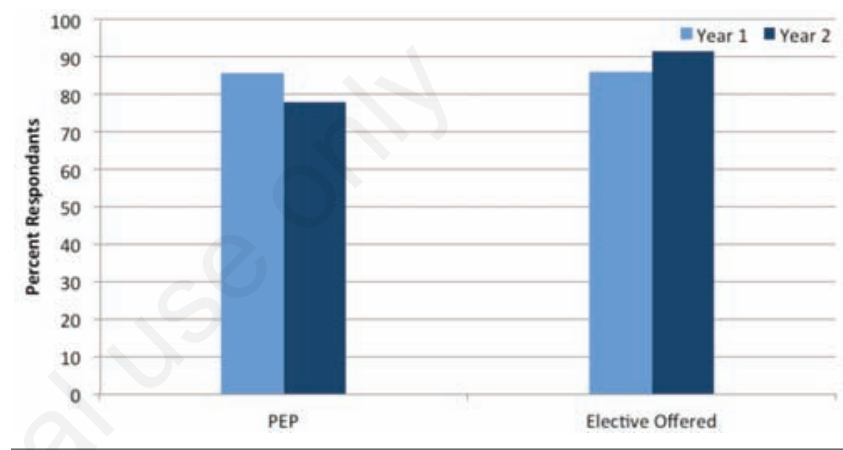

Figure 7. Faculty reporting satisfied or very satisfied with overall Professional Enrichment Program and elective. or very satisfied with PEP scheduling for opportunities to decompress, to better understand previous class material, to prepare for the next course, and to plan personal and family time. In Figure 3B, data are segregated by class to demonstrate differences. As shown, first year students reported they are more satisfied with the ability to decompress and take advantage of more time for personal or family needs than are second year students. Second year students were more satisfied than first year students with the opportunity to better understand academic material previously presented than were first year students.

Faculty had observed that as the second year curriculum progresses, students become increasingly distracted by approaching national licensing examinations. This is reflected in the results showing second year PEPs are not as effective at providing more personal and family time; increased studying and the lack of personal and family time are associated with the observed decreased ability to decompress during PEPs in the second year. Overall, the level of satisfaction increased over the initial three years of the new program (Figure 4). When queried annually about changing the scheduling of PEP, both classes overwhelmingly request to maintain it as scheduled.

A survey of faculty at the end of each PEP began in 2010 had a mean response rate of $42 \% \quad(n=44)$, much less than the $100 \%$ response of students. Faculty were asked to identify activities they participated in during the one or two week PEPs even if the activity did not involve students (Figure 5). As seen, the majority of faculty responding were engaged in electives. Faculty were also asked to respond to statements about the PEP experience (Figure 6). Overall, responding faculty are satisfied with the PEP experience. While electives are very satisfying for faculty, other aspects of PEPs for faculty need further investigation (Figure 7).

\section{Conclusions}

An innovative, new academic calendar provided several improvements to the medical educational program. The appeal of the program is the less intense curricular structure and the ability to select electives with material of interest to the student whether it is to study something in greater detail or to understand it better. Current and future efforts are focused on correlating improved outcomes with the Professional Enrichment Program. In addition, the impact of PEPs on faculty metrics is also being investigated.

\section{References}

1. Vitaliano PP, Maiuro RD, Russo J, et al. A biopsychosocial model of medical student distress. J Behav Med 1988;11:311-31.

2. Vitaliano, PP, Maiuro RD, Russo J, Mitchell ES. Medical student distress: a longitudinal study. J Nerv Ment Dis 1989;177:70-6.

3. Richman JA, Flaherty JA. Gender differences in medical student distress: contributions of prior socialization and current role-related stress. Soc Sci Med 1990;30: 777-87.

4. Whitehouse WG, Dinges DF, Orne EC, et al. Psychosocial and immune effects of self- 
hypnosis training for stress management throughout the first year of medical school. Psychosom Med 1996;58:248-63.

5. Dyrbye LN, Thomas MR, Massie FS, et al. Burnout and suicidal ideation among U.S. medical students. Ann Intern Med 2008;149: 334-41.

6. Dyrbye LN, Thomas MR, Eacher A, et al. Race, ethnicity, and medical student wellbeing in the United States. Arch Intern Med 2007;167:2013-9.

7. Dyrbye LN, Thomas MR, Huntington JL, et al. Personal life events and medical student burnout: a multicenter study. Acad Med 2006;8:374-84.

8. Hysenbegasi A, Hass SL, Rowland CR. The impact of depression on the academic productivity of university students. J Ment Health Pol Econom 2005;8:145-51.

9. Stewart SM, Lam TH, Betson CL, et al. A prospective analysis of stress and academic performance in the first two years of medical school. Med Educ 1999;33:243-50.

10. American College Health Association. Two more data sets enhance survey's overview of the health status of college students. Baltimore MD. 2003. Available from: http://www.acha-ncha.org/pr/pr_ncha_ 11_03_03.html. Accessed on: May 2013.

11. American College Health Association. National College Health Assessment Spring 2008 Reference Group Data Report (abridged): the American College Health Association. J Am Coll Health 2009;57:47788.

12. Sawatzky RG, Tatner PA, Richardson CG, et al. Stress and depression in students: the mediating role of stress management selfefficacy. Nurs Res 2012;61:13-21.

13. Paul G, Elam B, Verhulst ST. A longitudinal study of students' perceptions of using deep breathing meditation to reduce testing stresses. Teach Learn Med 2007;19:287-92.

14. Santana S. Mind-body treatments gain foothold in medial curriculum. AAMC Reporter 2005:8-9.

15. Lee J, Graham A. Students' perceptions of medical school stress and their evaluation of a wellness elective. Med Educ 2001;35:652-9.

16. Holm M, Tyssen R, Stordal KI, Haver B. Self-development groups reduce medical school stress: a controlled intervention study. BMC Med Educ 2010;10:23.

17. McGrady A, Brennan J, Lynch D, Whearty
K. Stress management intervention for first year medical students. Ann Behav Sci Med Educ 2010;16:15-9.

18. Information for Financial Aid Professionals (IFAP). 2012-2013 Federal Student Aid Handbook. Vol 3. Available from: http://ifap.ed.gov/fsahandbook/ attachments/Vol3Master1213Jun14.pdf. Accessed on: June 2012.

19. 34 Code of Federal Regulation. Title 34, subtitle B. Regulations of the Offices of the Department of Education. Chapter VI. Office of Postsecondary Education, Department of Education. Part 668.4 Payment period.

20. National Resident Matching Program, Data Release and Research Committee. Results of the 2012 NRMP Program Director Survey National Resident Matching Program, Washington, DC, 188 pp.

21. National Resident Matching Program, Charting Outcomes in the Match, 2011. National Resident Matching Program, Washington, DC, 268 pp. 